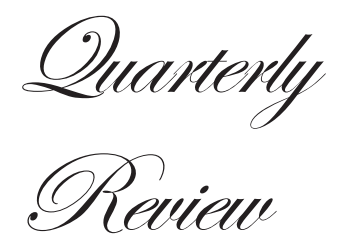

\title{
Primary versus secondary achalasia: A diagnostic conundrum
}

\author{
Pankaj Gupta ${ }^{1}$, Uma Debi ${ }^{2}$, Saroj Kant Sinha², Babu Ram Thapa ${ }^{2}$, \\ KaushalKishor Prasad ${ }^{2}$
}

\begin{abstract}
Department of Radiodiagnosis ${ }^{1}$ and

A coherent distinction between primary and secondary achalasia is considerably important to Superspeciality of

Gastroenterology ${ }^{2}$;

Postgraduate Institute of Medical

Education and Research,

Chandigarh, India

clinicians. This is because the therapeutic interventions for the two are entirely different.

Whilst pneumatic dilation is the standard treatment in primary achalasia, the same treatment, if instituted in malignant stenosis carries potential risk to the patient and delays appropriate therapy of the underlying disorder. This distinction however, is extremely difficult. None of

Correspondence to:

Dr. Kaushal Kishor Prasad

Email: kaushalkp10@hotmail.com, the available clinical, manometric, endoscopic or imaging criteria can reliably exclude secondary achalasia. However, suspicion may be raised and in such cases, an exhaustive work up including repeat biopsies and even surgery should be considered. In this review, we discuss prasadkaushalkishore@pgimeredu.in the various problems in differentiating primary from secondary achalasia.
\end{abstract}

KEYWORDS: Achalasia, esophagus, motility disorder, idiopathic, pseudoachalasia

\section{Introduction}

Achalasia, an esophageal motility disorder is characterized by a combination of absent primary peristalsis and impaired lower esophageal sphincter (LES) relaxation. ${ }^{1}$ Depending on the pathogenesis, it is classified into primary and secondary. Primary achalasia is idiopathic and characterised by degeneration of the inhibitory ganglion cells in the esophageal mesenteric plexuses ${ }^{2}$. Secondary achalasia, popularly known as pseudoachalasia, is usually related to malignant disease of gastroesophageal junction (GEJ). The most common neoplastic process associated with pseudoachalasia is carcinoma of the gastric cardia ${ }^{3}$. Relatively less common causes include esophageal carcinoma, metastatic disease and infective disorders like Chagas disease ${ }^{4}$. Rarely post-surgical states like post fundoplication and gastric banding can lead to secondary achalasia.

Diagnosis of achalasia is based primarily on clinical findings. Progressive dysphagia, more to liquids than solids, is a frequent presenting symptom. Confirmation of diagnosis is provided by manometric, radiographic and endoscopic evaluation. Although, diagnosis of achalasia is relatively straightforward, distinction of primary from secondary achalasia is a difficult task. This distinction, however assumes immense importance as management of the two conditions is entirely different. Where most patients with primary achalasia undergo pneumatic dilatations, such treatment in patients with secondary achalasia (misdiagnosed as primary achalasia) leads to an inadvertent delay in appropriate treatment of the underlying malignancy, progression to an advanced stage and 
shortened survival ${ }^{5}$.

There is significant overlap in the clinical profile (age at presentation, duration of symptoms) of patients with primary and secondary achalasia ${ }^{6}$. However, some studies have demonstrated the usefulness of certain clinical features in this differentiation. The gold standard investigation for diagnosis of achalasia is manometry. However, there are no distinguishing manometric features between achalasia and pseudoachalasia ${ }^{7}$. With advanced disease, retention of undigested food in the esophagus is seen ${ }^{8}$. In its ability to differentiate primary from secondary achalasia, endoscopy is neither sensitive nor specific. Thus, besides having a poor sensitivity and specificity in the diagnosis of achalasia, it is not always able to exclude pseudoachalasia.

Barium esophagogram in achalasia demonstrates a dilated, esophagus with smooth, tapered, symmetrical narrowing ("bird-beak narrowing") at the GEJ and no primary peristalsis during video fluoroscopy ${ }^{9}$. Early disease may be missed as the findings are more subtle. Based on available criteria on barium esophagogram, the differentiation of achalasia and pseudoachalasia is imprecise.

In this review, we highlight the pitfalls of the available methods to differentiate achalasia from pseudoachalasia.

\section{Pathophysiology}

The enteric nervous system (ENS) controls the esophageal peristalsis and relaxation of the LES. ENS is a complex network of nerve fibres surrounding the entire gastrointestinal tract (GIT). The activity of ENS is subject to modulation by the central nervous system via the vagus nerve. Myenteric plexus, located between the circular and longitudinal smooth muscle layers harbors the neurons of the ENS that control motility and peristalsis. There are two types of neurons in the mesenteric plexus with opposite actions. Inhibitory neurons secrete nitrous oxide (NO) and vasoactive intestinal peptide (VIP) and cause muscle relaxation. Excitatory neurons, on the other hand, use acetylcholine (Ach) and produce muscles contraction.

The major pathogenetic mechanism in achalasia is the degeneration of inhibitory neurons of the mesenteric plexus, preferentially those that innervate the LES and the distal esophagus selectively ${ }^{10-13}$. The unopposed action of the excitatory neurotransmitter such as acetylcholine results in high amplitude non-peristaltic contractions, leading to what is known as vigorous achalasia (Figure 1) in the initial stage of the disease. However, as the disease progresses, the cholinergic neurons also get affected, resulting in dilatation and low amplitude simultaneous contractions in the esophageal body"classic" achalasia (Figure 2).

These mechanisms are supported by the autopsy and invitro studies ${ }^{14,15}$. Autopsy studies have shown a reduction in the number of ganglion cells in the esophageal body and an inverse correlation between the number of ganglion cells and duration of disease. Cholecystokinin, which reduces LES pressure in healthy subjects, has been shown to increases pressure in patients with achalasia ${ }^{15}$. Similarly, esophageal distension failed to cause relaxation and gastric distension failed to induce transient LES relaxation in achalasia patients, further supporting the degenerative of ganglia with preserved response of the muscle fibres to acetylcholine. Although smooth muscle dysfunction in the distal esophagus and the GEJ are the main pathophysiological findings in achalasia, the role of the upper esophageal sphincter (UES) function in achalasia has not been fully explored. Some studies have reported abnormal functioning of the striated muscle in the region of $\mathrm{UES}^{16,17}$. In a study by Wauters et al ${ }^{18}$ baseline deglutitive UES function and the response of UES to pneumatic dilatation (PD) in patients with achalasia was studied using

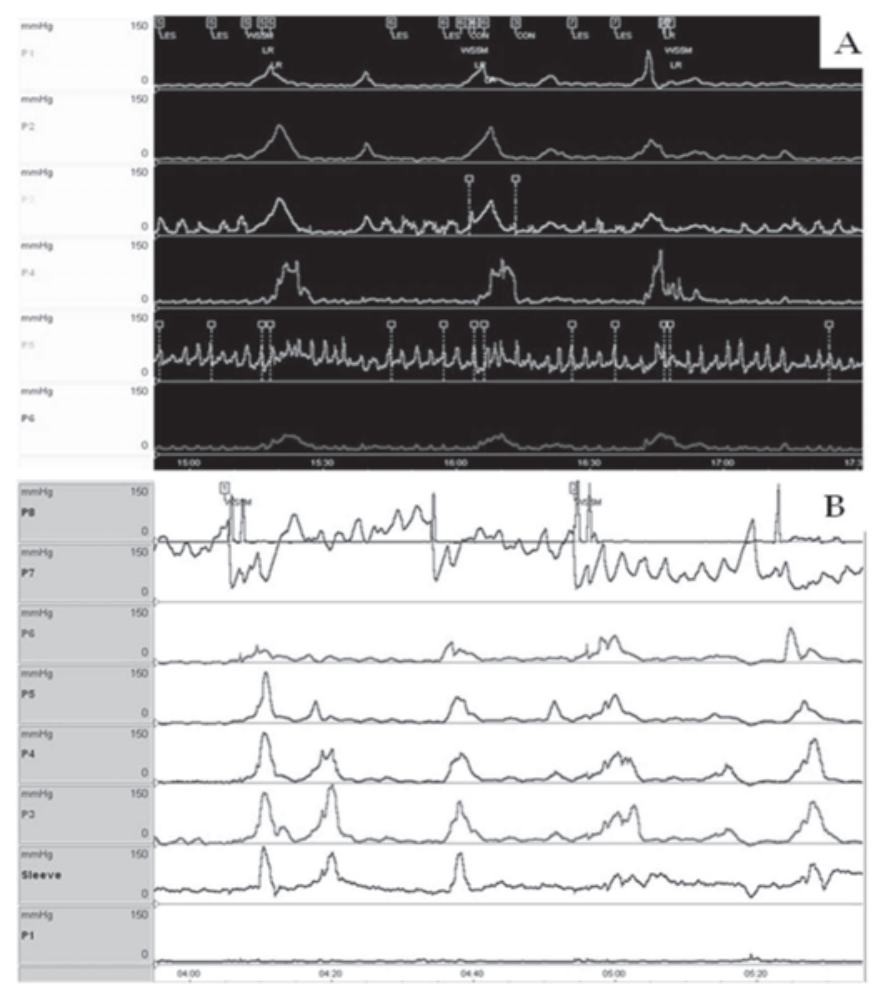

Figure 1: Manometric studies; A, B: Vigorous achalasia cardia on conventional manometry shows high resting pressure of LES with absence of swallow induced relaxation and aperistaltic esophageal body but tertiary contractions showing amplitude $>40 \mathrm{mmHg}(\mathrm{A}, \mathrm{B})$. Study performed with radial catheter $(A)$ and with sleeve catheter $(B)$. 
HRM. In 50 patients (mean age 52.7 518.6 years, 21 females), UES parameters were significantly reduced after initial PD. The effect of PD on UES function was significant in type II achalasia.

Though, the pathogenetic mechanism as discussed above is well established, the factors producing the aberration are not entirely known. ${ }^{12}$ Various putative mechanisms include infections, immunological mechanisms and genetic factors. Various viruses have been implicated based primarily on the indirect evidence. The candidate viruses belong to the human herpes virus family (herpes simplex virus 1 and 2, cytomegalovirus, varicella zoster virus, Epstein Barr virus and human herpes virus 6) ${ }^{19}$. An immunological basis of achalasia is supported by the presence of inflammatory cell infiltrate of the mesenteric plexus in $90 \%$ to $100 \%$ of esophageal specimens, the presence of autoantibody in sera and an association with major histocompatibility complex class a!antigen ${ }^{20}$. The genetic basis is supported by its occurrence in monozygotic twins and siblings, familial occurrence of achalasia cardia, genetic correlations of the genes like ALADIN and AAAS, association with other genetic diseases such as Down's syndrome and Parkinson disease and polymorphism involving the neurotransmitter genes (NOS, VIPR1, ILR23 and PTPN22) 21-24.

The cause of neurodegeneration is known in cases of secondary achalasia. Except Southern America, where most cases of secondary achalasia are caused by Trypanosoma cruzi (Chaga's disease), malignant process represents the most common cause. Adenocarcinoma of the esophago-gastric junction is the most common cause of secondary achalasia. Other causes include metastatic disease, paraneoplastic disease, benign lesions and iatrogenic conditions ${ }^{25-28}$. Few uncommon causes of secondary achalasia include pleural mesothelioma, esophageal leiomyomatosis, esophageal stromal tumor, multiple myeloma, pancreatic pseudocyst and encapsulating peritoneal sclerosis ${ }^{30-35}$. In a study by Katzka et al, amongst 17 cases of achalasia secondary to neoplasia, the most common causes were esophageal adenocarcinoma, followed by breast and non-small cell lung cancer ${ }^{36}$. Two cases of esophageal leiomyomatosis were detected. One case each of pancreatic and prostatic carcinoma was also noted. Liu et al in their study of 13 patients with secondary achalasia reported following causes: esophageal adenocarcinoma arising in Barrett's esophagus $(n=1)$, adenocarcinoma of the esophagogastric junction $(n=7)$, metastatic renal cell carcinoma to the esophagogastric junction $(n=1)$, breast adenocarcinoma $(\mathrm{n}=1)$, pulmonary small cell carcinoma $(\mathrm{n}=1)$, pleural malignant mesothelioma $(n=1)$, and mediastinal fibrosis $(n=1)^{37}$.

\section{Clinical presentation}

Age: Patients with primary achalasia are younger compared to those with secondary achalasia. Rozman et al compared 18 patients with secondary achalasia with 421 patients with idiopathic or primary achalasia ${ }^{7}$. The mean age in the secondary achalasia group was 57.1 years compared to 47.1 years for primary achalasia. Woodfield et $\mathrm{al}^{9}$ found that age of the patient was a significant, although less useful criterion for differentiating primary from secondary achalasia. While $80 \%$ of patients with secondary achalasia were older than 60 years, only $38 \%$ with primary achalasia were more than 60 years old. Tracey et $\mathrm{al}^{8}$ reported that $28 \%$ of patients with primary achalasia were more than 60 years old. Sandler et al ${ }^{6}$ also found that one-third of patient with primary achalasia were above that age of 60 years. Ortiz-Olvera et $\mathrm{al}^{38}$ among 159 patients with achalasia, 36 patients were above the age of 60 years. Gockel et $\mathrm{al}^{39}$ evaluated 5 patients with pseudoachalasia and reported a mean age at presentation of 52 years (range 28-62 years). Thus, in individual cases, age is not a useful discriminatory feature in separating achalasia from pseudoachalasia.

Duration of symptoms: Patients with primary achalasia have long standing history of dysphagia while those with secondary achalasia have short duration of symptoms. In the study by Rozman et al, the mean duration of symptoms in patients with secondary achalasia was 4.5 months ${ }^{7}$. The significant difference in the duration of symptoms was documented by Woodfield et $\mathrm{al}^{9}$ in their series of 39 patients ( 29 with primary and 10 with secondary achalasia) - In this study, all patients with secondary achalasia had dysphagia for duration of less than 4 months, whereas more than $95 \%$ patients with primary achalasia had dysphagia for more than 12 months. Tracey et al also found significantly shorter duration of dysphagia in pseudoachalasia cases (9.6 \pm 8.6 months) vs. achalasia cases (54.3 \pm 44.2 months). In a study by Gockel et $\mathrm{al}^{39}$ the duration of symptoms was highly variable ranging from 3 months to 28 months, however, the mean duration of symptoms was more than 12 months. Ortiz-Olvera et al ${ }^{38}$ evaluated the impact of age on the clinical presentation in adults with idiopathic achalasia. They found that chest pain was the only symptom that was significantly more common in the achalasia patients less than 60 year-old. The authors, however, did not study the differences in the 
presentation of primary and secondary achalasia.

Weight loss: In several studies, weight loss is comparable in both groups of achalasia. In the study by Rozman et al weight loss was reported in $88.2 \%$ of patients with secondary achalasia compared to $57.3 \%$ of patients with primary achalasia ${ }^{7}$. Reynold et al ${ }^{40}$ recorded weight loss in patients with achalasia at presentation and found mean weight loss to be less than 7 $\mathrm{kg}$ In a separate, study by Tucker et $\mathrm{al}^{10}$ mean weight loss was more than $7 \mathrm{~kg}$ in secondary achalasia group. In other studies, however, there was considerable overlap and this clinical parameter was not found to be clinically significant ${ }^{6,41}$.

\section{Manometric findings}

Typical manometric findings in achalasia include combination of esophageal aperistalsis, poorly relaxing LES or hypertensive LES (Figure 2). However, in clinical practice often only one of these, esophageal aperistalsis may be found. In several studies, the role of manometry in distinguishing primary from secondary achalasia has been proven to be non-contributory. Woodfield et $\mathrm{al}^{9}$ reported typical manometric findings in $80 \%$ of patients $(n=29)$. In the same study, the authors evaluated 10 patients with secondary achalasia and found no distinguishing features. Similarly, Kahrilas et $\mathrm{al}^{41}$ in their study on 161 patients with primary achalasia and 6 patients with secondary achalasia concluded that conventional esophageal manometry fails to discriminate achalasia from pseudoachalasia. Tracey et al ${ }^{8}$ also found no obvious feature on conventional manometry to distinguish primary from secondary achalasia. Thus, conventional esophageal manometry, though highly sensitive in the diagnosis of achalasia has no role in distinguishing primary from secondary achalasia. High-resolution manometry (HRM) systems have brought a paradigm change in the imaging evaluation of achalasia. Unlike conventional manometry systems where the output is in terms of polygraph and line tracing, outputting pressure data in HRM systems is in esophageal pressure topography (EPT) ${ }^{42}$. With the introduction of HRM, diagnostic criteria for achalasia have become more rigid and clinically relevant physiological subtypes have been reported $^{43}$. Integrated relaxation pressure (IRP) is a new metric devised for EPT to quantify GEJ relaxation. Studies using HRM have explored the prognostic value of manometry in achalasia subtypes. The achalasia subtypes as proposed by the Chicago classification for HRM include Type I to III, based on esophageal body contractility and pressurization ${ }^{43}$. Type I is characterized by absent peristalsis and no discernible esophageal contractility with an elevated IRP. Type II is associated with abnormal GEJ relaxation and pressurization in the entire esophageal in excess of $30 \mathrm{~mm} \mathrm{Hg}$. Type III achalasia is associated with premature contractions and impaired GEJ relaxation. In a study by Roman et $\mathrm{al}^{44}$ the Chicago classification was applied to a multicentre French cohort of achalasia. They compared the clinical and manometric characteristics between the 3 subtypes. Among 169 patients, 14\% classified as type I, $70 \%$ as type II and $16 \%$ as type III. Type III patients were older than types I and II. This may suggest a different pathophysiology. There was no significant difference in the clinical presentation among the three groups. GEJ and upper

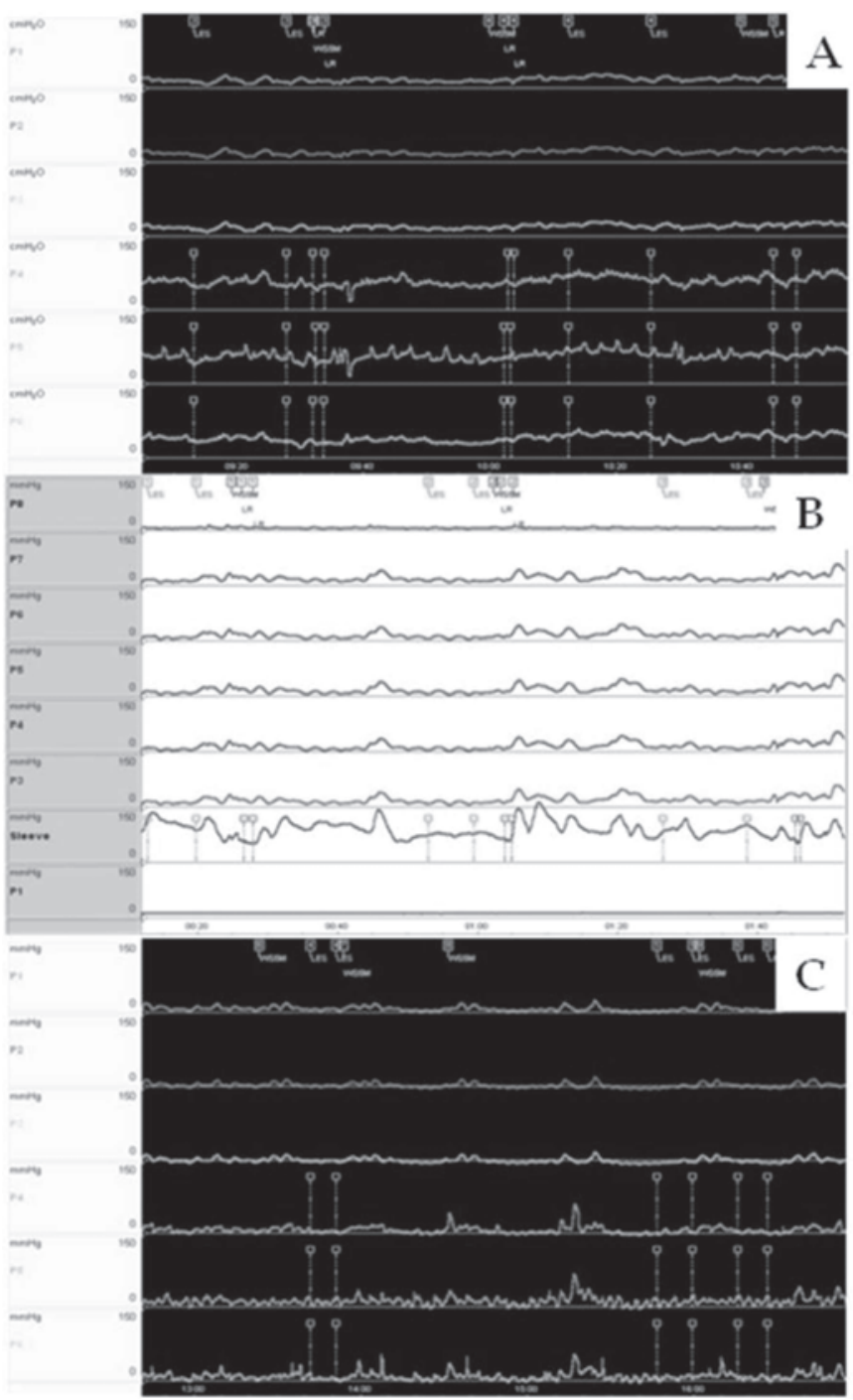

Figure 2: Manometric studies; A, B, C: Classic achalasia cardia on conventional manometry shows high resting pressure of LES with absence of swallow induced relaxation and aperistaltic esophageal body (A, B). Study performed with radial catheter (A) and with sleeve catheter (B). Same patient after pneumatic dilatation shows resting LES pressure returned to normal but esophageal body is aperistaltic (C). 


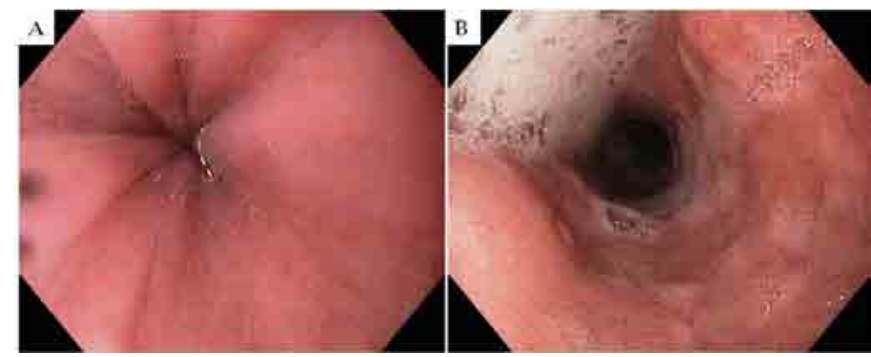

Figure 3: Endoscopic images; A, B: Lower end of esophagus showing tightly closed lower esophageal sphincter with normal appearing esophageal mucosa (A). Normal esophageal mucosa but esophagus is dilated and shows presence of liquid residue suggesting distal obstruction (B).

oesophageal sphincter pressures did not differ between the 3 groups. Another important observation from HRM studies is a group of patients with impaired GEJ relaxation but some preserved peristalsis. This group is now recognized as a distinct variant phenotype of achalasia. Importantly, such a manometric pattern can be a manifestation of other disease entities including secondary achalasia ${ }^{13}$.

\section{Endoscopic and surgical findings}

There is limited role of endoscopy in evaluating patients with primary achalasia. Evaluation of esophageal peristalsis and LES status during endoscopy are not very accurate. Even lack of peristalsis and difficulty in negotiating LES are neither sensitive nor specific. Retention of undigested food in the esophagus, though more specific (Figure 3), occurs only in patients with advanced disease ${ }^{6}$. Ominous findings on endoscopy that suggest a diagnosis of secondary achalasia include mucosal ulceration, nodularity, growth and submucosal or extrinsic bulge ${ }^{41}$. Endoscopy can however be misleading in cases where no obvious growth is noted. Tracey et al ${ }^{8}$ in their study on 5 patients with secondary achalasia reported difficult passage of the endoscope through the GEJ in all the patients. However, a diagnosis of malignancy was offered in only two patients. Woodfield et al $^{9}$ evaluated endoscopic findings in 10 patients with achalasia and found that the endoscope could not be negotiated beyond LES in 4 patients. In all patients, diagnosis of malignancy was established at surgery. In the series by Woodfield et $\mathrm{al}^{9} 3$ patients had esophageal carcinoma, 3 had carcinoma of cardia, 3 had lung carcinoma with disseminated mediastinal nodal disease and one patient had endometrial carcinoma. Gockel et $\mathrm{al}^{39}$ in their analysis of literature found a total of 264 cases of pseudoachalasia in 122 publications Malignant disease was most common followed by benign lesions, sequel of surgical procedures at the distal esophagus or proximal stomach and rarely paraneoplastic process due to distant neuronal involvement- Primary malignancy was found more common than metastases. Among primary malignant disease, carcinoma of the GEJ comprised more than $50 \%$ of the cases.

Recently the role of endoscopic ultrasound (EUS) and EUS guided fine need aspiration has been reported in establishing the diagnosis and malignancy near the GEJ and hence differentiating primary from secondary achalasia ${ }^{45.46}$. Similarly some studies have also reported the utility of laparoscopy and
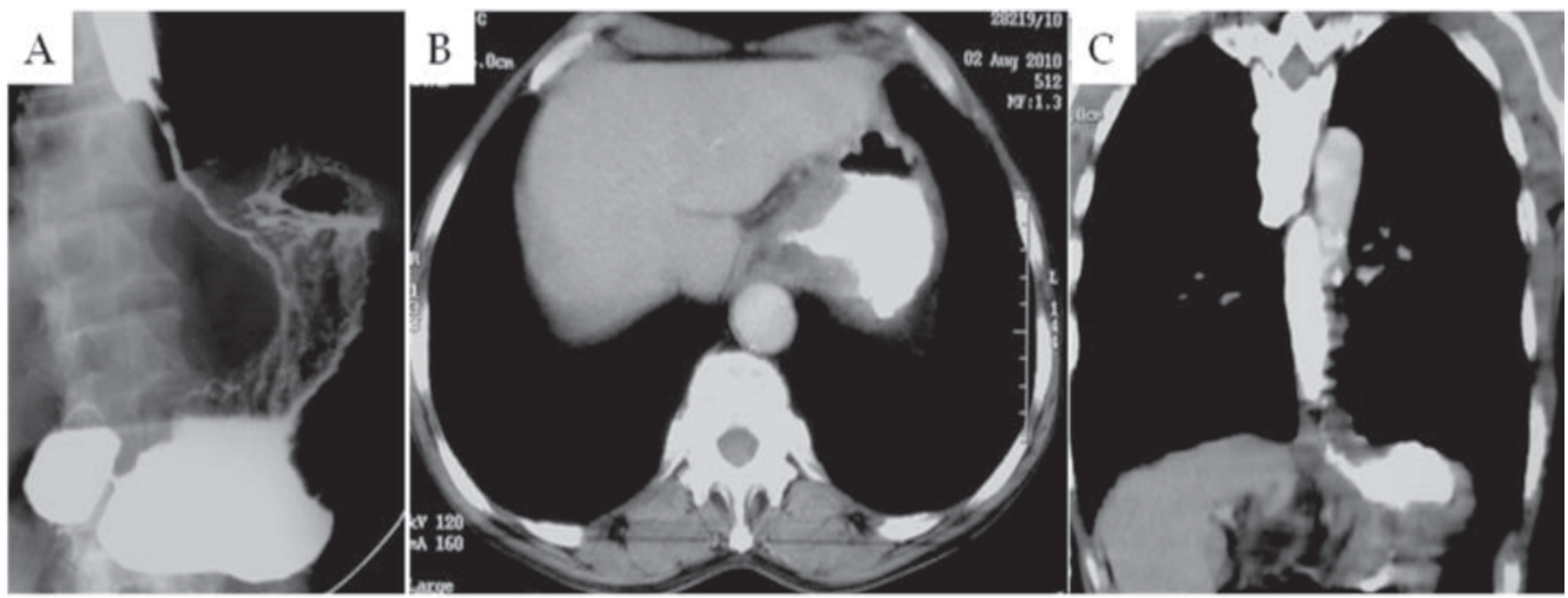

Figure 4: Imaging studies; A, B, C: Barium esophagogram shows typical findings of secondary achalasia related to malignant disease process. An eccentric, long segment stricture with reduce distensibility and mucosal destruction in distal thoracic esophagus extending across GE junction. Shouldering and proximal hold up is also noted (A). Reduce distensibility of fundus and proximal body of stomach is also noted with irregularity of mucosa. CECT chest (B) and multiplanar reconstruction (C) images of same patient shows circumferential mural thickening of distal esophagus extending across GE junction to fundus and proximal stomach. Significant luminal compromise of esophagus is noted with proximal hold up. 
mediastinoscopy in establishing a diagnosis in a patient strongly suspected to have secondary achalasia ${ }^{47}$.

\section{Radiological findings \\ Barium swallow}

Only a single large retrospective study reviewing the barium findings in primary and secondary achalasia is available. In this study Woodfield et $\mathrm{al}^{9}$ reviewed records of 29 patients with primary achalasia and 10 patients with secondary achalasia. They reviewed the radiographs to determine the morphologic features of the narrowed distal esophageal segment, gastric cardia and fundus. They proposed that pseudoachalasia should be strongly considered if esophagogram reveal a narrowed distal esophageal segment longer than $3.5 \mathrm{~cm}$ with little or no proximal dilatation (Figure 4A). The degree of esophageal dilatation above the narrowed segment was also found to be a significantly important criterion differentiating secondary achalasia from primary achalasia (Figure 5A). Classic findings of secondary achalasia (eccentric stricture with nodularity and shouldering) were found in only $40 \%$ of patients. In our study, classic findings of secondary achalasia were noted in $70 \%$ patients. The remaining 30\% patients showed distal esophageal segment indistinguishable from primary achalasia (Figure 6) ${ }^{49}$. In our study, we proposed new signs on barium esophagogram that help distinguish primary from secondary achalasia. These included tram-track sign, filling defects within the stricture segment and tertiary contractions ${ }^{49}$.

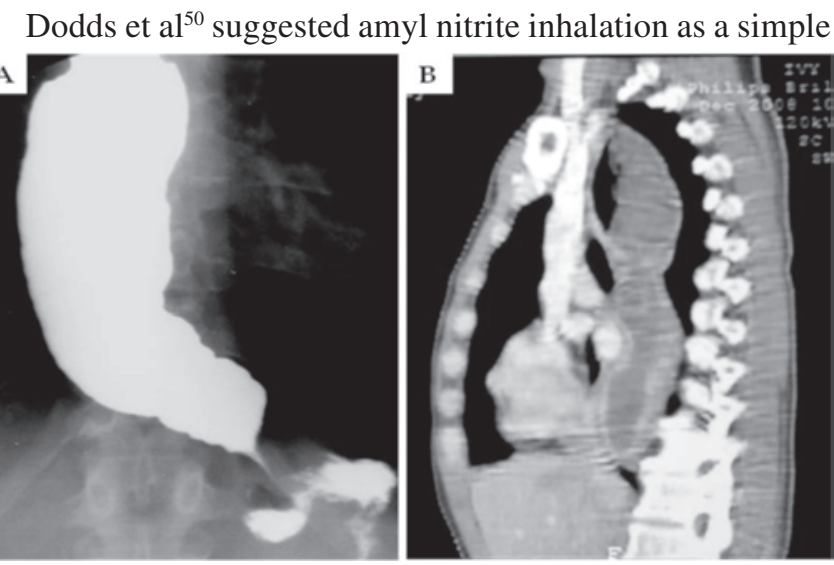

Figure 5: Imaging studies; A, B: Barium esophagogram shows typical findings of primary achalasia. A short segment smooth, symmetrical tapered narrowing of the lower end of esophagus with hold up and dilated and tortuous proximal esophagus seen (A). CECT sagittal reformation of the same patient shows dilated and tortuous esophagus with air bubble in proximal portion (B). method for differentiating primary and secondary achalasia on barium studies. Amyl nitrite, a smooth-muscle relaxant was shown to have an increase of $2 \mathrm{~mm}$ or more in the caliber of the segment in primary achalasia but no effect on the narrowed distal esophageal segment in secondary achalasia. However, in the current setting, this technique is not popular.

In our experience, the statistical significance of length of abnormal distal esophageal segment and caliber of the esophagus above the stricture in differentiating primary $(\mathrm{n}=30)$ from secondary achalasia $(n=17)$ was confirmed ${ }^{49}$. However, rather than measuring the absolute esophagus length and caliber (in $\mathrm{cm}$ ), we compared these with the vertebral body height as this methods seems to be easily applicable and less cumbersome. Tertiary contractions were noted in $25 \%$ patients with secondary achalasia while they were noted in $90 \%$ patients with primary achalasia. Filling defects were noted in the distal esophageal segment in more than $90 \%$ patients of secondary achalasia.

\section{Computed Tomography (CT) findings}

Although barium studies have been the focus of researchers for differentiating primary from secondary achalasia, CT may also be useful in these patients (Figure 4B, $4 \mathrm{C} \& \mathbf{5 B}$ ). In patients with primary achalasia (Figure 5B), CT typically reveals little or no esophageal wall thickening or mass at the

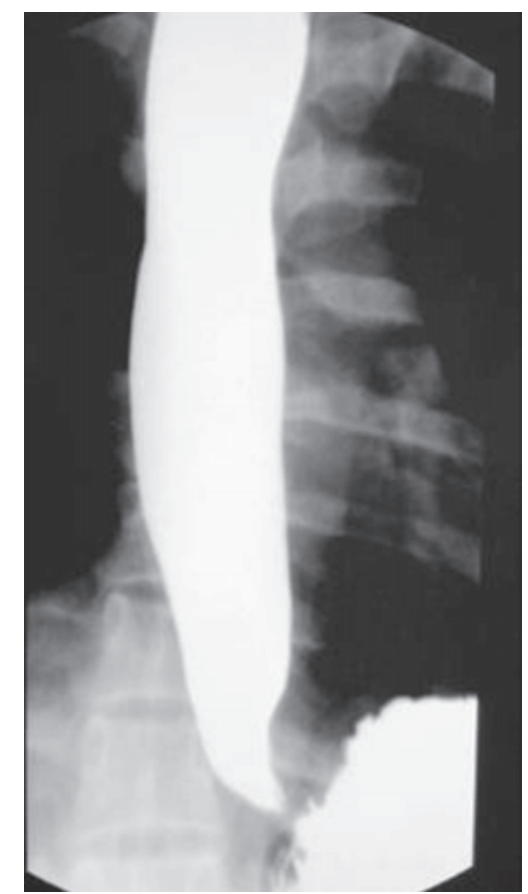

Figure 6: Imaging study; Barium esophagogram in a patient with secondary achalasia related to malignant disease process. The findings mimic those of primary achalasia. 
cardia. A potential pitfall however is the presence of a pseudo mass at the cardia because of inadequate distension of this region $^{32}$. Carter et $\mathrm{al}^{52}$ in their series of 12 patients with the manometric diagnosis of achalasia could distinguish patients with secondary achalasia from those with primary achalasia on the basis of marked and/or asymmetric thickening of the esophageal wall. They used a cut-off of $10 \mathrm{~mm}$ for esophageal wall thickening. Besides, CT may identify the site of the primary tumor in patients with secondary achalasia caused by metastatic tumors. Rabushka et $\mathrm{al}^{53}$ recorded CT findings in 12 patients with manometrically suspected diagnosis of achalasia. Nine patients were finally diagnosed as having primary and 3 patients as having secondary achalasia. CT findings in primary achalasia group were mild to moderate dilatation of esophagus with normal wall thickness. In contrast, authors reported atypical degree of dilatation/ wall thickness in secondary achalasia group.

\section{Autoantibody detection}

Studies have reported the utility of detection of autoantibodies in diagnosis of secondary achalasia with paraneoplastic etiology. A small proportion of patients show no evidence of neoplastic involvement of the GEJ but demonstrate antineuronal antibodies, most often ANNA-1. Katzka et al. In their study of 17 patients with secondary achalasia detected autoantibodies in 5 patients $^{36}$. These included ANNA-1 and anti-acetylcholine antibody. Liu et al described a patient with small cell lung cancer with achalasia-like symptoms ${ }^{37}$. However, there was no radiographic or histological involvement of the esophagogastric junction. This patient had ANNA-1 antibodies suggesting a paraneoplastic dysmotility. Hejazi et al reported a patient with gastroparesis, pseudoachalasia and impaired intestinal motility as paraneoplastic manifestation of small cell lung carcinoma who tested positive for anti-Hu antibody ${ }^{26}$. Besides, auto-antibodies are detected in a large percentage of patients with primary achalasia. A recent study suggests that the $60 \%$ of patients with primary achalasia have circulating anti-GAD-65 antibodies ${ }^{54}$.

\section{Management}

The various treatment options for achalasia include oral pharmacological agents, botulinum toxin injection, pneumatic balloon dilatation (Figure 2C) and laparoscopic myotomy (Heller) or peroral endoscopic myotomy (POEM). Oral pharmacological agents (including calcium channel blockers, nitrates and phosophodiestarase inhibitors) act by reducing lower esophageal sphincter pressure ${ }^{55}$. However, they provide modest relief of symptoms at best and hence are not popular. Injection of botulinum toxin into the LES blocks the release of neurotransmitters at presynaptic cholinergic nerve endings of the terminal plate, resulting in a decreased LES pressure. This form of treatment is not effective in all patients. Best results are seen in those with vigorous achalasia ${ }^{56} \cdot$ Moreover, the benefit lasts for 6-12 months, repeat injection is required and additional treatments may be hindered. Advantage over pneumatic balloon dilatation and surgery is that it is less invasive with decreased complication rates and hence may be used in patients with too high risk for other treatment options ${ }^{57}$. Salvador $\mathrm{R}$ et al ${ }^{58}$ in a recent prospective study comprising 571 patients, however, found that LHM can be used even in elderly patients with an acceptable surgical risk A Among the three groups (d"45, 45-70 and e"70 years), there was no significant difference in terms of the morbidity and conversion rates. Mucosal tears were more common and post-operative hospital stay was longer in e"70 years group but this difference was not statistically significant $(\mathrm{p}=0.09)$.

Pneumatic dilatation (PD) presents the most common form of treatment for primary achalasia. During this procedure, endoscopy is performed and the Rigiflex balloon is positioned across the LES under fluoroscopic guidance (Figure 7). This is followed by slow inflation to 10 PSI for 15 seconds ${ }^{59}$. Patients

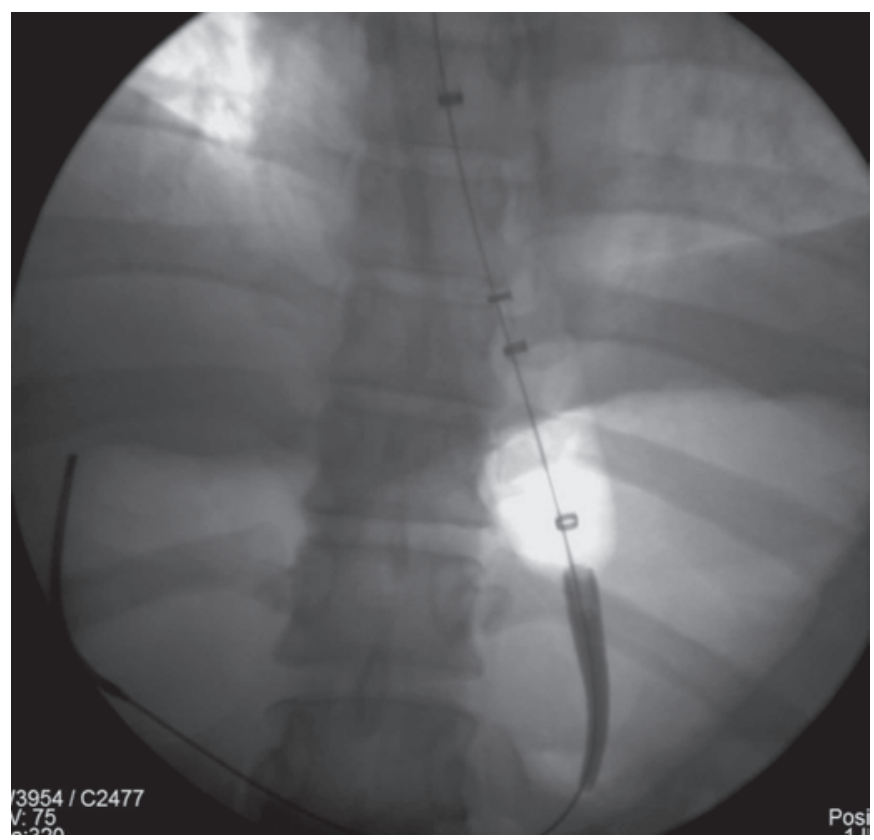

Figure 7: Flouroscopic image; Pneumatic dilatation for achalasia cardia using Rigiflex balloon. Balloon is fully inflated with waist completely obliterated. 
with persistent symptoms are offered a repeat procedure ${ }^{60}$. Pneumatic balloon dilatation is associated with a long term (510 years) clinical response rates ranging from $42 \%$ to $85 \%$.

Laparoscopic Heller myotomy (LHM) has become the standard surgical technique replacing the open procedure ${ }^{61}$. Symptom improvement after LHM ranged from $83 \%$ to $100 \%$ in the first year and sustained remission rates of $67-85 \%$ were found in long term studies ${ }^{62}$.

The efficacy of PD with LHM has been compared in several recent studies. ${ }^{63,64}$ LHM has been shown to have comparable or superior efficacy compared to PD with slightly higher perforation rate.

Inoue $\mathrm{H}$ et al ${ }^{65}$ reported a significant reduction of symptoms and LES pressure, following POEM after a mean follow up of 5 months. However, small patient cohort and short follow up period were substantial limitations of these studies. Additionally, the safety of POEM and comparison of its therapeutic effect with PD or LHM remains to be validated.

Secondary achalasia treatment is based on the underlying etiology and the stage of the disease. Misdiagnosis of secondary achalasia as primary achalasia can result in pneumatic balloon dilatations or LHM. These forms of treatments not only delay the appropriate management of underlying malignancy but also add to the complications.

\section{Future perspective}

The role of advanced diagnostic techniques, including functional MRI (f-MRI) and endoluminal functional lumen imaging probe (EndoFLIP) system, has been reported in the context of primary achalasia ${ }^{66-69}$. However these techniques have not been utilized in evaluating suspected secondary achalasia. Refinement of these techniques will definitely allow their use in the differentiation of primary from secondary achalasia in near future.

\section{Conclusion}

The diagnosis of secondary achalasia is difficult to establish by conventional diagnostic measures. However, pseudoachalasia should always be considered on the basis of a constellation of findings including advanced age, rapid weight loss, and difficulty in passing the endoscope through the GEJ. In such cases, even negative biopsies and radiological findings (including CT and barium studies) should not lead to a false reassurance of a benign disorder. Multiple biopsies and even surgical exploration is required to diagnose secondary achalasia so that appropriate management plans can be instituted in a timely fashion.

\section{References}

1. Paterson WG. Etiology and pathogenesis of achalasia. Gastrointest Endosc Clin NAm. 2001;11:249-66.

2. Cassella RR, Brown AL, Sayre GP, Ellis FH. Achalasia of the esophagus: pathologic and etiologic considerations. Ann Surg. 1964;160:474-87.

3. Parkman HP, Cohen S. Malignancy-induced secondary achalasia. Dysphagia. 1994;9:292-6.

4. Portale G, Costantini M, Zaninotto G, Ruol A, Guirroli E, Rampado $\mathrm{S}$, et al. Pseudoachalasia: not only esophago-gastric cancer. Dis Esophagus. 2007;20:168-72.

5. Pohl D, Tutuian R. Achalasia: an Overview of Diagnosis and Treatment. J Gastrointestin Liver Dis. 2007;16:297-303.

6. Sandler RS, Bozymski EM, Orlando RC. Failure of clinical criteria to distinguish between primary achalasia and achalasia secondary to tumor. Dig Dis Sci. 1982;27:209-13.

7. Rozman RW, Achkar E. Features distinguishing secondary achalasia from primary achalasia. Am J Gastroenterol. 1990;85:1327_30.

8. Tracey JP, Traube M. Difficulties in the diagnosis of pseudoachalasia. Am J Gastroenterol. 1994;89:2014-8.

9. Woodfield CA, Levine MS, Rubesin SE, Langlotz CP, Laufer I. Diagnosis of primary versus secondary achalasia: reassessment of clinical and radiographic criteria. AJR Am J Roentgenol. 2000;175:727-31.

10. Tucker HJ, Snape WJ, Cohen S. Achalasia secondary to carcinoma: manometric and clinical features. Ann Intern Med. 1978;89:315-8 .

11. Ott DJ, Richter JE, Chen YM, Wu WC, Gelfand DW, Castell DO. Esophageal radiography and manometry: Correlation in 172 patients with dysphagia. Am J Roentgenol. 1987;149:307-11.

12. Ghoshal UC, Daschakraborty SB, Singh R. Pathogenesis of achalasia cardia. World J Gastroenterol. 2012;18:3050-7.

13. Pandolfino JE, Kahrilas PJ. Presentation, diagnosis, and management of achalasia. Clin Gastroenterol Hepatol. 2013;11:887-97.

14. Park W, Vaezi MF. Etiology and pathogenesis of achalasia: the current understanding. Am J Gastroenterol. 2005;100:1404-14.

15. Holloway RH, Wyman JB, Dent J. Failure of transient lower oesophageal sphincter relaxation in response to gastric distension in patients with achalasia: evidence for neural mediation of transient lower oesophageal sphincter relaxations. Gut. 1989;30:762-7.

16. Yoneyama F, Miyachi M, Nimura Y. Manometric findings of the upper esophageal sphincter in esophageal achalasia. World J Surg. 1998;22:1043-7.

17. De Vault KR. Incomplete upper esophageal sphincter relaxation: association with achalasia but not other esophageal motility disorders. Dysphagia. 1997;12:157-60.

18. Wauters L, Van Oudenhove L, Selleslagh M, Vanuytsel T, Boeckxstaens G, Tack J, et al. Balloon dilation of the esophago- 
gastric junction affects lower and upper esophageal sphincter function in achalasia. Neurogastroenterol Motil. 2014;26:69-76.

19. Facco M, Brun P, Baesso I, Costantini M, Rizzetto C, Berto A, et al. T cells in the mesenteric plexus of achalasia patients show a skewed TCR repertoire and react to HSV-1 antigens. Am J Gastroenterol. 2008;103:1598-609.

20. Latiano A, De Giorgio R, Volta U, Palmieri O, Zagaria C, Stanghellini V, et al. HLA and enteric antineuronal antibodies in patients with achalasia. Neurogastroenterol Motil. 2006;18:520-5.

21. Jung KW, Yoon IJ, Kim do H, Chung JW, Choi KS, Choi KD, et al. Genetic evaluation of ALADIN gene in early-onset achalasia and alacrima patients. J Neurogastroenterol Motil. 2011;17:169-73.

22. Vigo AG, Martínez A, de la Concha EG, Urcelay E, Ruiz de Leon A. Suggested association of NOS2A polymorphism in idiopathic achalasia: no evidence in a large case-control study. Am J Gastroenterol. 2009;104:1326-7.

23. Prpic I, Huebner A, Persic M, Handschug K, Pavletic M. Triple A syndrome: genotype-phenotype assessment. Clin Genet. 2003;63:415-7.

24. Moore SW. Down syndrome and the enteric nervous system. Pediatr Surg Int 2008;24:873-83.

25. Ghoshal UC, Sachdeva S, Sharma A, Gupta A, Misra A. Cholangiocarcinoma presenting with severe gastroparesis and pseudoachalasia. Indian J Gastroenterol. 2005;24:167-8.

26. Hejazi RA, Zhang D, McCallum RW. Gastroparesis, pseudoachalasia and impaired intestinal motility as paraneoplastic manifestation of small cell lung carcinoma. Am J Med Sci. 2009;338:69-71.

27. Pastor DM, Eggers AD, Drabick JJ, Loughran TP, Baryerl MG, Shope TR. Retroperitoneal diffuse large B-cell lymphoma presenting as pseudoachalasia. J Clin Onco. 2010;28:e184-7.

28. Pesce A, Scilletta R, Branca A, Portale TR, Puleo S. A rare case of pancreatic cancer presenting as pseudoachalasia. Ann Ital Chir. 2012;2012.

29. Lopez-Liuchi JV, Kraytem A, Uldry PY. Oesophageal achalasia secondary to pleural mesothelioma. J R Soc Med. 1999:92;24-5.

30. Ulla JL, Fernandez-Salgado E, Alvarez V, Ibanez A, Soto S, Carpio $\mathrm{D}$, et al. pseudoachalasia of the cardia secondary to nongastrointestinal neoplasia. Dysphagia 2008;23:122-6.

31. Ray S, Saluja SS, Gupta R, Chattopadhyay TK. Esophageal leiomyomatosis: an unusual cause of pseudoachalasia. Can $J$ Gastroenterol 2008:22;187-9.

32. Mohamed A. Education and Imaging. Gastrointestinal: pseudoachalasia caused by a lower esophageal stromal tumor. $J$ Gastroenterol Hepatol. 2009;24:1152.

33. Lazaraki G, Nakos A, Katodritou E, Pilpilidis I, Tarpagos A, Katsos I. A rare case of multiple myeloma initially presenting with pseudoachalasia. Dis Esophagus. 2009;22:E21-4.

34. Colarian JH, Sekkarie M, Rao R. Pancreatic pseudocyst mimicking idiopathic achalasia. Am J Gastroenterol. 1998;93:103-5.

35. Forgacs B, Shiell K, Farquharson F, Tavakoli A, Makanjuola D, Augustine T, et al. Pseudoachalasia of the esophagus caused by encapsulating peritoneal sclerosis. Perit Dial Int 2010;30;246-9.

36. Katzka DA, Farrugia G, Arora AS. Achalasia secondary to neoplasia: a disease with a changing differential diagnosis. Dis
Esophagus. 2012;25:331-6.

37. Liu W, Fackler W, Rice TW, Richter JE, Achkar E, Goldblum JR. The pathogenesis of pseudoachalasia: a clinicopathologic study of 13 cases of a rare entity. Am J Surg Pathol. 2002;26:784-8.

38. Ortiz-Olvera N, González-Martínez M, Dehesa-Violante M, Morán-Villota S. Clinical and manometric findings on elderly patients with achalasia. Rev Gastroenterol Mex. 2011;76:231-6.

39. Gockel I, Eckardt VF, Schmitt T, Junginger T. Pseudoachalasia: a case series and analysis of the literature. Scan J Gastroenterol. 2005;40:378-85.

40. Reynolds JC, Parkman HP. Achalasia. Gastroenterol Clin North Am. 1989;18:223-55.

41. Kahrilas PJ, Kishk SM, Helm JF, Dodds WJ, Harig JM, Hogan WJ. Comparison of pseudoachalasia and achalasia. Am J Med. 1987;82:439-46.

42. Pandolfino JE, Kwiatek MA, Nealis T, Bulsiewicz, Post J, Kahrilas PJ. Achalasia: a new clinically relevant classification by high-resolution manometry. Gastroenterology. 2008;135:1526-33.

43. Bredenoord AJ, Fox M, Kahrilas PJ, Pandolfino JE, Schwizer W, Smout AJ, et al. Chicago classification criteria of esophageal motility disorders defined in high resolution esophageal pressure topography. Neurogastroenterol Motil. 2012;24:57-65.

44. Roman S, Zerbib F, Quenehervé L, Clermidy H, Varannes SB, Mion F. The Chicago classification for achalasia in a French multicentric cohort. Dig Liver Dis. 2012;44:976-80.

45. Roushan N, Zolfaghari A, Asadi M, Taslimi R. Pseudoachalasia: a diagnostic challenge. Med J Islam Repub Iran. 2014:28;54.

46. Saino G, Bano D, Nencioni M, Rubino B, Banovina L. Laparoscopic diagnosis of pleural mesothelioma presenting with pseudoachalasia. World J Gastroenterol. 2009;15:3569-72.

47. Lucchinetti CF, Kimmel DW, Lennon VA. Paraneoplastic and oncologic profile of patients seropositive for type 1 antineuronal nuclear antibodies. Neurology. 1998;50:652-7.

48. Chuah SK, Kuo CM, Wu KL, Hu TH, Wang CC, Chiu YC, et al. Pseudoachalasia in a patient after truncal vagotomy surgery successfully treated by subsequent pneumatic dilations. World $J$ Gastroenterol. 2006;12:5087-90.

49. Dodds WJ, Stewart ET, Kishk SM, Kahrilas PJ, Hogan WJ. Radiologic amyl nitrite test for distinguishing pseudoachalasia from idiopathic achalasia. Am J Roentgenol. 1986;146:21-3.

50. Gupta P, Debi U, Sinha SK, Prasad KK. Primary versus secondary achalasia: New signs on barium esophagogram. Indian J Radiol Imag. 2015 (ahead of print)

51. Marks WM, Callen PW, Moss AA. Gastroesophageal region: source of confusion on CT. Am J Roentgenol. 1981;136:359-62.

52. Carter M, Deckmann RC, Smith RC, Burrell MI, Traube M. Differentiation of achalasia from pseudoachalasia by computed tomography. Am J Gastroenterol. 1997;92:624-8.

53. Rabushka LS, Fishman EK, Kuhlman JE. CT evaluation of achalasia. J Comput Assist Tomogr. 1991;15:434-9.

54. Kraichely RE, Farrugia G, Pittock SJ, Castell DO, Lennon VA. Neural autoantibody profile of primary achalasia. Dig Dis Sci. 2010;55:307-11.

55. Wen ZH, Gardener E, Wang YP. Nitrates for achalasia. Cochrane Database Syst Rev. 2004:CD002299.

56. Annese V, Bassotti G, Coccia G, Dinelli M, D’Onofrio V, Gatto 
G, et al. A multicentre randomised study of intrasphincteric botulinum toxin in patients with oesophageal achalasia. GISMAD Achalasia Study Group. Gut. 2000;46:597-600.

57. Rohof WO, Boeckxstaens GE. New insights in pathophysiology and management of achalasia. J Pediatr Gastroenterol Nutr. 2011;53:S17-9.

58. Salvador R, Costantini M, Cavallin F, Zanatta L, Finotti E, Longo C, et al. Laparoscopic Heller myotomy can be used as primary therapy for esophageal achalasia regardless of age. J Gastrointest Surg. 2014;18:106-11.

59. Richter JE, Boeckxstaens GE. Management of achalasia: surgery or pneumatic dilation. Gut. 2011;60:869-76.

60. Wong RK. Pneumatic dilation for achalasia. Am J Gastroenterol. 2004;99:578-80

61. Ishaq S. Treatment of achalasia: the role of laparoscopic cardiomyotomy needs to be emphasized. Am J Gastroenterol. 2004;99:2278-9.

62. Spechler SJ. AGA technical review on treatment of patients with dysphagia caused by benign disorders of the distal esophagus. Gastroenterology. 1999;117:233-54.

63. Boeckxstaens GE, Annese V, Varannes SB, Chaussade S, Costantini M, Cuttitta A, et al; European Achalasia Trial Investigators. Pneumatic dilation versus laparoscopic heller's myotomy for idiopathic achalasia. $N$ Eng $J$ Med.
2011;364:1807-16.

64. Schoenberg MB, Marx S, Kersten JF, Rösch T, Belle S, Kähler $\mathrm{G}$, et al. Laparoscopic Heller myotomy versus endoscopic balloon dilatation for the treatment of achalasia: a network meta-analysis. Ann Surg. 2013;258:943-52.

65. Inoue H, Minami H, Kobayashi Y, Sato Y, Kaga M, Suzuki M, et al. Peroral endoscopic myotomy (POEM) for esophageal achalasia. Endoscopy. 2010;42:265-71.

66. Miyazaki Y, Nakajima K, Sumikawa M, Yamasaki M, Takahashi $\mathrm{T}$, Miyata $\mathrm{H}$, et al. Magnetic resonance imaging for simultaneous morphological and functional evaluation of esophageal motility disorders. Surg Today. 2014:44;668-76.

67. Panebianco V, Habib FI, Tomei E, Paolantonio P, Anzidei M, Laghi A, et al. Initial experience with magnetic resonance fluoroscopy in the evaluation of oesophageal motility disorders. Comparison with manometry and barium fluoroscopy. Eur Radiol. 2006:16;1926-33.

68. McMahon BP, Frokjaer JB, Kunwald P, Liao D, Funch-Jensen $\mathrm{P}$, Drewes AM, et al. The functional lumen imaging probe (FLIP) for evaluation of the esophagogastric junction. Am J Physiol Gastrointest Liver Physiol. 2007;292:G377-G384

69. Massey BT. EndoFLIP assessment of achalasia therapy: Interpreting the distensibility data is a bit of a stretch. Gastroenterology. 2013;144:e17-8. 